\title{
Fasting Serum Levels of Potassium and Sodium in Relation to Long-Term Risk of Cancer in Healthy Men
}

This article was published in the following Dove Press journal: Clinical Epidemiology

\author{
Ragnhild S Falk (D) \\ Trond Heir ${ }^{2,3}$ \\ Trude E Robsahm (iD ${ }^{4}$ \\ Steinar Tretli $\mathbb{D}^{4}$ \\ Leiv Sandvik' \\ Jan E Erikssen ${ }^{2}$ \\ Jan E Paulsen (iD ${ }^{5}$ \\ 'Oslo Centre for Biostatistics and \\ Epidemiology, Oslo University Hospital, \\ Oslo, Norway; ${ }^{2}$ Oslo Ischemia study, \\ Oslo University Hospital, Oslo, Norway; \\ ${ }^{3}$ Institute of Clinical Medicine, Faculty of \\ Medicine, University of Oslo, Oslo, \\ Norway; ${ }^{4}$ Department of Research, \\ Cancer Registry of Norway, Oslo, \\ Norway; ${ }^{5}$ Department of Food Safety and \\ Infection Biology, Norwegian University \\ of Life Sciences, Oslo, Norway
}

Correspondence: Ragnhild S Falk Oslo Centre for Biostatistics and Epidemiology, Oslo University Hospital, $\mathrm{Pb} 4950$ Nydalen, Oslo 0424, Norway

Tel +472306 6013

Email rs@ous-hf.no
Purpose: To examine whether serum levels of potassium and sodium were associated with long-term cancer risk in initially healthy men.

Patients and Methods: A cohort of 1994 initially healthy men with no use of medication, aged 40-59 years, was followed for cancer during 40 years of follow-up. Associations between fasting electrolyte levels and cancer risk were assessed with incidence rates and Cox proportional hazards models.

Results: Potassium, but not sodium, was linearly associated with cancer risk. This association remained significant after adjustment of several potential confounding factors, and also after excluding the first 10 years of follow-up. The age-adjusted risk of all-site cancer increased with $16 \%$ for each SD increase in potassium level. Men with hyperkalemia showed an incidence rate that was $40 \%$ higher than for men with normal potassium levels.

Conclusion: Fasting serum potassium level in healthy men was positively associated with long-term cancer risk. Potassium or potassium ion channels may have a role in cell proliferation or differentiation. These findings might imply future cancer strategies for targeting individuals with high serum potassium levels.

Keywords: cancer incidence, cell proliferation, electrolyte levels, epidemiology, prospective cohort study

\section{Introduction}

Electrolyte levels of potassium and sodium have been a topic of interest in the aetiology of cancer for many years. In the 1980s, several observations aroused suspicion of cancer being associated with dietary or body content of potassium and sodium. ${ }^{1,2}$ More recently, the nature and function of specific ion channels have been suggested to be involved in tumor development and progression. ${ }^{3-8}$

Moreover, elevated levels of potassium and lowered levels of sodium have been found in patients with various types of cancer, ${ }^{3,9-11}$ probably due to oxidative damage $^{12}$ or cancer cell lysis. ${ }^{13,14}$ Thus, extracellular electrolyte concentration may be linked to the diagnosis of cancer, either because the electrolyte composition may facilitate cancer development or result from an ongoing undetected cancer disease. However, the associations between potassium or sodium and development of cancer have not been studied in healthy individuals.

In the current study, we aimed to prospectively examine relationships between fasting serum levels of sodium and potassium in initially healthy middle-aged and the incidence of cancer during 40 years of follow-up. 


\section{Materials and Methods}

\section{Data Sources}

The Oslo Ischemia Study is a comprehensive health survey that was established in 1972 aimed to examine risk factors for coronary heart disease and other cardiovascular diseases in a healthy male population. A total of 2341 male employees in five companies in Oslo, Norway, aged 40-59 years, were invited to participate in the period August 1972-March 1975. Inclusion of the study required the absence of any disorders and no use of medication last 14 days. Among those invited, 2014 (86\%) agreed to participate and completed the study protocol. At inclusion, all participants underwent a comprehensive review of medical history, clinical and physical examinations (including measurements of body height and weight), a panel of blood tests, and a maximal exercise tolerance bicycle test. In addition, information on lifestyle variables (eg, smoking habits) was collected with a questionnaire. Detailed selection and implementation procedures have previously been reported. ${ }^{15-17}$

The outcome of the study was the incidence of all-site cancer- and site-specific cancers. Information on cancer and vital status were obtained by linking the cohort data to the Cancer Registry of Norway using the 11-digit personal identification number assigned all Norwegian citizens after 1960. The Cancer Registry has registered data on all cancer diagnosed since 1953. Mandatory reporting on all malignancies from several independent sources ensures data completeness and high data quality, whereof the proportion of morphologically verified cases was $94 \%{ }^{18}$ The cancer data obtained comprised information on cancer site based on the 7th (in the former period; 1970-1992) and 10th (in the latter period; 1993-present) edition of the World Health Organization's International Classification of Diseases and date of diagnosis.

At inclusion, all participants provided informed consent according to the Declaration of Helsinki. In the 1990s, after increased awareness of privacy, the Data Protection Authority retrospectively reviewed the inclusion process for the Oslo Ischemia Study and judged participation to be in accordance with provisions on written informed consent. The study has further been approved by the Regional Committees for Medical and Health Research Ethics, Norway.

\section{Variables}

Blood samples for determination of sodium and potassium were performed after at least $12 \mathrm{~h}$ fasting and 8 $\mathrm{h}$ abstaining from smoking. Repeated analysis of the blood samples showed high accuracy. ${ }^{15}$ The electrolytes were considered both as continuous and as categorical variables. The continuous relationship was given per 1 standard deviation (SD) increase. Potassium level below the normal range was categorized as hypokalemia $(\leq 3.5$ $\mathrm{mmol} / \mathrm{L})$, and as hyperkalemia if above $(>5.0 \mathrm{mmol} / \mathrm{L}){ }^{19}$ Sodium levels were categorized as hyponatremia if $<136$ $\mathrm{mmol} / \mathrm{L}^{20}$ and as hypernatremia if $>145 \mathrm{mmol} / \mathrm{L}^{21}$ Normal levels were divided into three equally spaced categories both for potassium $(3.6-4.0,4.1-4.5$, and 4.6-5.0 mmol/L) and sodium (136-138, 139-142, and $143-145 \mathrm{mmol} / \mathrm{L})$. The ratio of sodium to potassium was calculated as a measure of the electrical potential of the cell.

Body mass index was calculated based on the individual's measured body height and weight at baseline $(\mathrm{kg} /$ $\mathrm{m}^{2}$ ). Physical fitness was measured as the total work (ie, sum of the work performed in a bicycle test) divided by body weight $(\mathrm{kJ} / \mathrm{kg})$. Information on smoking habits was collected by questionnaire, and individuals were categorized as "never", "former", or "present" smokers. The erythrocyte sedimentation rate was determined by the Westergren method ( $\mathrm{mm} /$ hour). In addition, serum creatinine $(\mathrm{mg} / \mathrm{dL})$, triglyceride $(\mathrm{mmol} / \mathrm{L})$, and total cholesterol $(\mathrm{mmol} / \mathrm{L})$ were measured in all subjects.

The cohort of men was followed for cancer throughout 2012. Of the 2014 men included, we excluded two men with

Table I Baseline Characteristics of the Study Cohort, N=1994 Initially Healthy Men

\begin{tabular}{|l|l|l|}
\hline Characteristic & Mean & Standard Deviation \\
\hline Age (years) & 49.8 & 5.5 \\
Weight (kg) & 76.8 & 9.9 \\
Height (cm) & 176.8 & 6.2 \\
Body mass index (kg/m²) & 24.6 & 2.8 \\
Physical fitness (kJ/kg) & 1.43 & 0.56 \\
Potassium (mmol/L) ${ }^{\mathrm{a}}$ & 4.35 & 0.35 \\
Sodium (mmol/L) $^{\mathrm{b}}$ & 141.2 & 3.5 \\
Potassium-to-sodium ratio a,b & 32.7 & 2.8 \\
Triglycerides (mmol/L) & 1.32 & 0.71 \\
Cholesterol (mmol/L) & 6.7 & 1.2 \\
Creatinine (mg/dL) & 0.93 & 0.15 \\
Sedimentation rate (mm/hour) & 7.4 & 6.7 \\
Smoking, Never [n(\%)] & 502 & 25.2 \\
Former [n(\%)] & 619 & 31.0 \\
Present [n(\%)] & 873 & 43.8 \\
\hline
\end{tabular}

Notes: Data are mean (standard deviation) unless otherwise stated. ${ }^{\text {a Missing }}$ information for potassium in 5 men. 'Missing information for sodium in 88 men. 
missing vital status data and 15 men due to cancer diagnosis prior to the date of the examination. Further, three men did not obtain values for neither potassium nor sodium. Thus, 1994 men remained in the cohort for statistical analyses.

\section{Statistical Analyses}

Descriptive analyses were conducted for baseline characteristics and presented as frequencies, proportions, mean, SD, and range. Test for trend across ordered categories of potassium and sodium was performed by a Wilcoxon test.

The men were followed longitudinally from the date of examination (baseline) to the date of cancer diagnosis, death, emigration, age of 85 years, or the end of followup, whichever occurred first.

The absolute risk of all-site cancer by levels of electrolyte concentration was presented as age-adjusted incidence rates per 1000 person-years. Graphically, the cumulative incidence of all-site cancer in the presence of competing risk was obtained through the AalenJohansen estimator

The relative risk of all-site cancer was explored through a set of Cox-regression models. To explore the potential bias caused by death as a competing event, a similar set of regression model was performed with death without previous cancer as the event of interest.

Table 2 Baseline Characteristics of the Study Cohort Stratified by Fasting Level of (A) Potassium and (B) Sodium (mmol/L) in Five Groups

\begin{tabular}{|c|c|c|c|c|c|}
\hline $\begin{array}{l}\text { A } \\
\text { Characteristic }\end{array}$ & $\begin{array}{l}\text { Hypokalemia } \\
\leq 3.5 \\
n=19\end{array}$ & $\begin{array}{l}\text { Normal-Low } \\
3.6-4.0 \\
n=330\end{array}$ & $\begin{array}{l}\text { Normal-Intermediate } \\
4.1-4.5 \\
n=I 155\end{array}$ & $\begin{array}{l}\text { Normal-High } \\
4.6-5.0 \\
n=435\end{array}$ & $\begin{array}{l}\text { Hyperkalemia } \\
>5.0 \\
n=50\end{array}$ \\
\hline Age (years) & $48.8(5.1)$ & $48.6(5.6)$ & $49.8(5.5)$ & $50.6(5.3)$ & $51.6(4.5)$ \\
\hline Weight (kg) & $75.9(7.9)$ & $77.1(10.1)$ & $77.3(9.7)$ & $75.6(10.3)$ & $74.4(9.8)$ \\
\hline Height $(\mathrm{cm})$ & $174.6(5.7)$ & $177.0(6.4)$ & $176.8(6.2)$ & $176.5(6.1)$ & $177.3(5.8)$ \\
\hline Body mass index $\left(\mathrm{kg} / \mathrm{m}^{2}\right)$ & $24.9(2.2)$ & $24.6(2.9)$ & $24.7(2.7)$ & $24.2(2.7)$ & $23.6(2.7)$ \\
\hline Physical fitness (kJ/kg) & $1.52(0.64)$ & $1.53(0.63)$ & $1.43(0.56)$ & $1.38(0.52)$ & $1.32(0.44)$ \\
\hline Triglycerides (mmol/L) & $1.39(0.67)$ & $1.27(0.66)$ & I. $37(0.76)$ & $1.25(0.64)$ & $1.27(0.48)$ \\
\hline Cholesterol (mmol/L) & $7.1(1.4)$ & $6.5(1.2)$ & $6.7(1.2)$ & $6.6(1.3)$ & $6.7(1.1)$ \\
\hline Creatinine $(\mathrm{mg} / \mathrm{dL})$ & $0.98(0.13)$ & $0.92(0.16)$ & $0.93(0.15)$ & $0.93(0.16)$ & $0.97(0.16)$ \\
\hline Sedimentation rate ( $\mathrm{mm} / \mathrm{hour}$ ) & $7.3(7.2)$ & $6.2(5.1)$ & $7.3(6.6)$ & $8.2(7.2)$ & $8.7(8.5)$ \\
\hline Sodium (mmol/L) & $139.6(2.6)$ & $140.8(3.5)$ & $|4| .2(4.5)$ & $14 \mid .6(3.5)$ & $143.0(4.5)$ \\
\hline Smoking, Never [n(\%)] & II (57.9) & $105(31.8)$ & $278(24.1)$ & $98(22.5)$ & $8(16.0)$ \\
\hline Former $[\mathrm{n}(\%)]$ & $2(10.5)$ & $123(37.3)$ & $374(32.4)$ & $107(24.6)$ & $13(26.0)$ \\
\hline Present $[\mathrm{n}(\%)]$ & $6(31.6)$ & $102(30.9)$ & $503(43.6)$ & $230(52.9)$ & $29(58.0)$ \\
\hline B & $\begin{array}{l}\text { Hyponatremia } \\
<136 \\
n=55\end{array}$ & $\begin{array}{l}\text { Normal-low } \\
\mid 36-138 \\
n=33 \mid\end{array}$ & $\begin{array}{l}\text { Normal-intermediate } \\
\text { |39-| } 42 \\
n=927\end{array}$ & $\begin{array}{l}\text { Normal-high } \\
|43-| 45 \\
n=4 \mid \text { | }\end{array}$ & $\begin{array}{l}\text { Hypernatremia } \\
>145 \\
n=182\end{array}$ \\
\hline Age (years) & $50.0(5.2)$ & $50.1(5.3)$ & $49.6(5.6)$ & $49.6(5.4)$ & $49.9(5.4)$ \\
\hline Weight (kg) & $78.1(10.4)$ & $76.8(10.3)$ & $76.9(9.5)$ & $77.0(10.5)$ & $76.0(9.9)$ \\
\hline Height $(\mathrm{cm})$ & $176.0(6.5)$ & $176.7(6.4)$ & $176.9(6.2)$ & $177.2(6.2)$ & $175.8(5.8)$ \\
\hline Body mass index $\left(\mathrm{kg} / \mathrm{m}^{2}\right)$ & $25.1(2.5)$ & $24.6(2.8)$ & $24.6(2.8)$ & $24.5(2.8)$ & $24.6(2.7)$ \\
\hline Physical fitness (kJ/kg) & $1.33(0.55)$ & $\mathrm{I} .44(0.60)$ & I. $46(0.56)$ & $\mathrm{I} .45(0.56)$ & $1.39(0.53)$ \\
\hline Triglycerides (mmol/L) & I.44 (0.89) & $1.43(0.94)$ & $1.29(0.64)$ & $1.32(0.67)$ & I.3। (0.57) \\
\hline Cholesterol (mmol/L) & $6.8(1.3)$ & $6.8(1.2)$ & $6.6(1.2)$ & $6.6(1.2)$ & $6.5(1.1)$ \\
\hline Creatinine (mg/dL) & $0.90(0.15)$ & $0.91(0.15)$ & $0.92(0.15)$ & $0.94(0.16)$ & $0.97(0.16)$ \\
\hline Sedimentation rate ( $\mathrm{mm} / \mathrm{hour}$ ) & $9.5(9.2)$ & $7.9(8.7)$ & $7.3(6.0)$ & $7.1(6.0)$ & $6.5(5.9)$ \\
\hline Potassium (mmol/L) & $4.2(0.30)$ & $4.3(0.34)$ & $4.3(0.35)$ & $4.4(0.33)$ & $4.5(0.39)$ \\
\hline Smoking, Never [n(\%)] & $15(27.3)$ & 79 (23.9) & $25 I(27.1)$ & $88(21.4)$ & $48(26.4)$ \\
\hline Former $[\mathrm{n}(\%)]$ & $13(23.6)$ & $96(29.0)$ & $300(32.4)$ & $129(31.4)$ & $53(29.1)$ \\
\hline Present $[\mathrm{n}(\%)]$ & 27 (49.1) & $156(47.1)$ & $376(40.6)$ & $194(47.2)$ & 81 (44.5) \\
\hline
\end{tabular}

Notes: Data are mean (standard deviation) unless otherwise stated. Missing information for potassium in 5 men and for sodium in 88 men. 
For each of the regression models, hazard ratios (HR) with $95 \%$ confidence intervals (CI) were calculated. Crude models and age-adjusted models were performed, in addition to models were the following potential confounding covariates were included: body mass index, smoking, physical fitness, triglycerides, cholesterol, creatinine, and sedimentation rate, all measured at baseline. Additionally, the level of sodium or potassium was included in the model to investigate the independent effects of the electrolytes. The proportionality of hazards assumption was met for all covariates, except smoking. Thus, we performed a stratified Cox model on smoking, where the baseline hazards were allowed to differ between never, former and present smokers. No interactions between the exposure of interest (potassium and sodium) and the adjusting covariates were observed.

To explore the continuous relationship between the electrolytes and all-site cancer risk we presented graphically the smoothed age-adjusted risk estimate from Coxregression analysis. Restricted cubic spline function with four knots chosen according to Harrell's recommended percentiles was used for this purpose.

When studying potassium, two secondary analyses were performed. First, to explore the possibility of reverse causality (ie, where high levels of potassium result from an ongoing cancer disease) we performed an analysis restricted to men that remained alive and cancer-free 10 years after baseline, ie, the first 10 years of observation were excluded and the new time zero was set 10 years after the initial baseline. Secondly, we calculated the risk for the most prevalent cancer sites in the study cohort by levels of potassium. The Cox model adjusted for age was used for this purpose due to the small number of events in several of the cancer sites.

Finally, the association between sodium-to-potassium ratio and cancer risk was explored in a similar manner to explore the electrical potential of the cell.

An association was considered statistically significant when $\mathrm{p}<0.05$. All statistical analyses were performed using Stata. ${ }^{22}$

\section{Results}

Mean age at inclusion into the study was 49.8 years (SD 5.5 years). The mean levels of potassium and sodium were $4.3 \mathrm{mmol} / \mathrm{L}$ (SD 0.35, range 1.9-7.0) and $141 \mathrm{mmol} / \mathrm{L}$ (SD 3.5 , range 107-161), respectively (Table 1). During follow-up (median 26.4 years, range $0.1-40.3$ years), 710 men were diagnosed with cancer, and 1248 deaths occurred (739 without previous cancer).
The level of potassium was positively associated with age, sedimentation rate, sodium and presence of smoking, and negatively associated with body mass index and fitness while the level of sodium was positively associated with creatinine and potassium and negatively associated with sedimentation rate (Table 2).

An increase in level of potassium increased the absolute risk of all-site cancer; the age-adjusted incidence rate was $2.1,12.3,14.5,14.9$, and 20.3 per 1000 person-years for potassium levels $\leq 3.5,3.6-4.0,4.1-4.5,4.6-5.0$, and $>5.0 \mathrm{mmol} / \mathrm{L}$, respectively (Table 3 ). Men with hyperkalemia showed an incidence rate that was $40 \%$ higher than for men with normal potassium levels. The cumulative incidence of all-site cancer increased continuously during the study period (Figure 1). In particular, among men with hyperkalemia, the cumulative incidence of all-site cancer started to deviate from lower levels of potassium at 5 years. For sodium, no differences in absolute risk were observed (Table 3, Figure 1).

The age-adjusted HR of all-site cancer showed a linear relationship with the increasing level of potassium (Figure 2). For each increase of $1 \mathrm{SD}(0.35 \mathrm{mmol} / \mathrm{L})$, a $16 \%$ increase in all-site cancer risk was observed (HR 1.16, 95\% CI

Table 3 Number of All-Site Cancer Cases (Events), Person-Years (Pyrs) and Age-Adjusted Incidence Rates (IR) with 95\% Confidence Intervals $(\mathrm{Cl})$ Among Initially Healthy Men During 40 years of Follow-Up by Fasting Level of Potassium and Sodium at Baseline

\begin{tabular}{|c|c|c|c|}
\hline & Events & Pyrs & $\begin{array}{l}\text { Age-Adjusted }^{\mathrm{a}} \\
\text { IR per } 1000 \text { pyrs } \\
(95 \% \mathrm{CI})\end{array}$ \\
\hline \multicolumn{4}{|l|}{ Potassium $^{\mathrm{b}}(\mathrm{mmol} / \mathrm{L})$} \\
\hline Hypokalemia $(\leq 3.5)$ & I & 556 & $2.1(0.3-14.7)$ \\
\hline Normal low $(3.6-4.0)$ & 107 & 9252 & $12.3(8.3-18.3)$ \\
\hline $\begin{array}{l}\text { Normal intermediate } \\
(4.1-4.5)\end{array}$ & 421 & 29,861 & $14.5(\mid 2.0-17.6)$ \\
\hline Normal high (4.6-5.0) & 156 & 10,447 & $14.9(10.9-20.4)$ \\
\hline Hyperkalemia $(>5)$ & 24 & 997 & $20.3(10.4-40.7)$ \\
\hline \multicolumn{4}{|l|}{ Sodium $^{c}(\mathrm{mmol} / \mathrm{L})$} \\
\hline Hyponatremia $(<136)$ & 20 & 1395 & $15.7(6.8-37.3)$ \\
\hline Normal low (136-I38) & 121 & 8319 & I5.I (I0.6-2I.5) \\
\hline $\begin{array}{l}\text { Normal intermediate } \\
(139-142)\end{array}$ & 338 & 24,161 & $14.4(\mid 1.7-17.9)$ \\
\hline Normal high (143-145) & 144 & 10,779 & $13.6(9.9-18.9)$ \\
\hline Hypernatremia $(>145)$ & 69 & 4522 & $16.1(10.1-25.7)$ \\
\hline
\end{tabular}

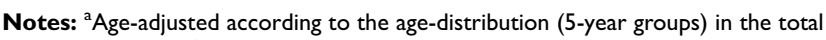
cohort at baseline. ${ }^{b}$ Missing information for potassium in 5 men, of which one with cancer. ${ }^{C}$ Missing information for sodium in 88 men, of which 18 with cancer. 

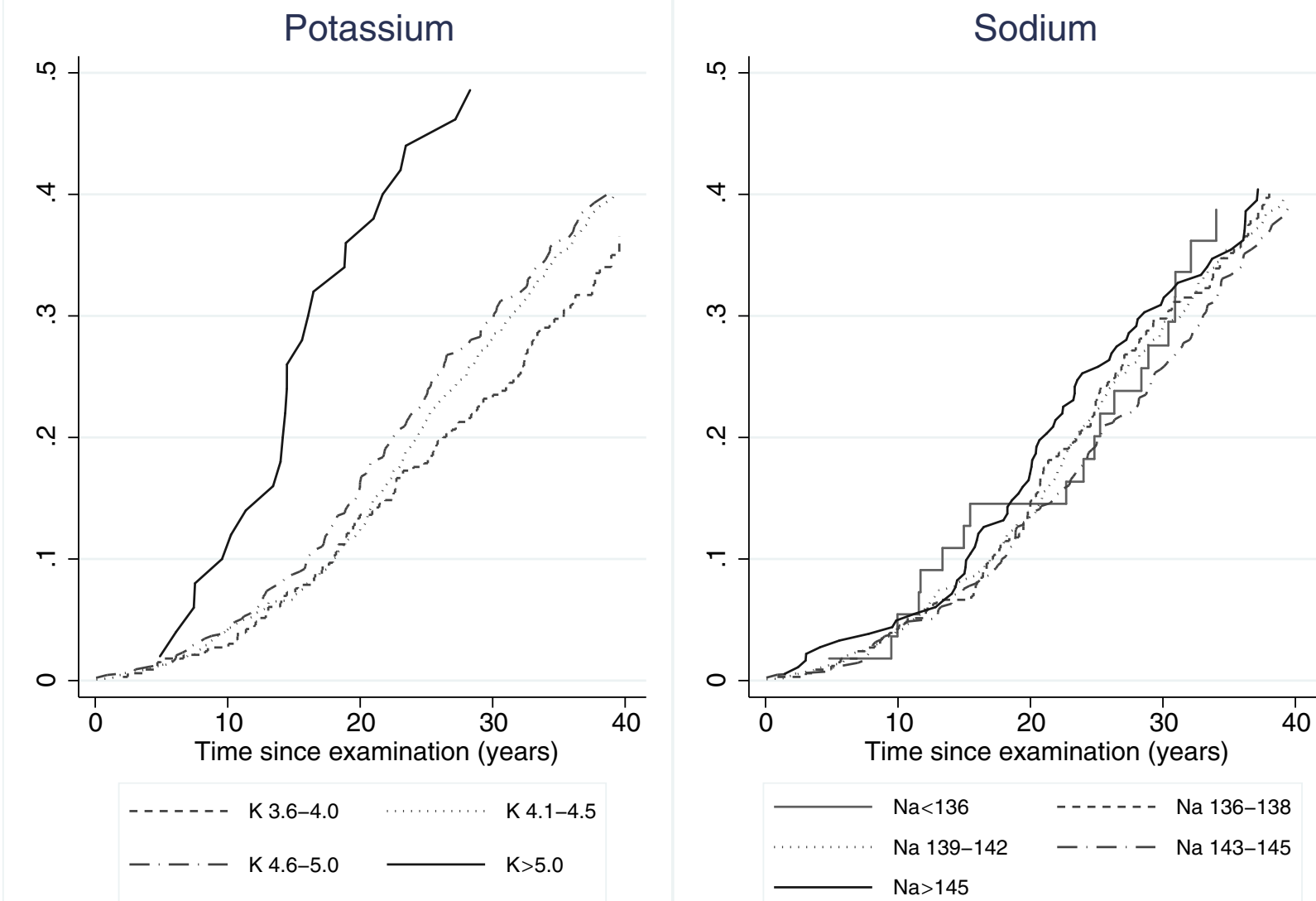

Figure I Cumulative incidence of all-site cancer by levels of potassium and sodium. $K \leq 3.5$ is not present due to only one cancer event.

1.08-1.25) (Table 4). The HR remained significant after additional adjustment of several potential confounding factors (see methods). Further, the association was independent of level of sodium, as shown in the last regression model, where the risk increased $15 \%$ per SD (HR 1.15, 95\% CI 1.06-1.24). Excluding the first 10 years of the study period did not affect the findings in the regression analyses. Moreover, the site-specific analyses showed positive associations for cancer in the stomach (HR 1.58, 95\% CI 1.17-2.13), pancreas $(1.69,1.26-2.26)$, lung $(1.32,1.09-1.59)$, and prostate $(1.16,1.01-1.34)$ (Table 5). Studying competing death as the outcome, the HR also increased by increasing the level of potassium (Table S1).

For sodium, no association with cancer risk was observed (Figure 2, Table 4). Sodium-to-potassium ratio was negatively associated with the risk of all-site cancer (Table S2). However, after adjustment for baseline level of potassium (the last regression model), no independent effect of the ratio was observed.

\section{Discussion}

In this prospective study, we investigated whether fasting serum levels of potassium and sodium in initially healthy middle-aged men was related to cancer risk during 40 years of follow-up. A continuous linear relationship was observed between serum potassium and cancer risk. For each increase in potassium level by $1 \mathrm{SD}$, the age-adjusted risk of all-site cancer increased with $16 \%$; the incidence increase was seen for cancers of pancreas (69\%), stomach (58\%), lung (32\%), and prostate $(16 \%)$. Individuals with hyperkalemia showed the highest cancer risk, which was found already after 5 years of follow-up. The association was evident after adjusting for a series of baseline characteristics (body mass index, fitness, smoking, triglycerides, cholesterol, creatinine, and sedimentation rate) and also after excluding the first 10 years of follow-up. Serum levels of sodium were not associated with cancer risk.

To our knowledge, the present study is the first to report that higher levels of serum potassium in healthy individuals 

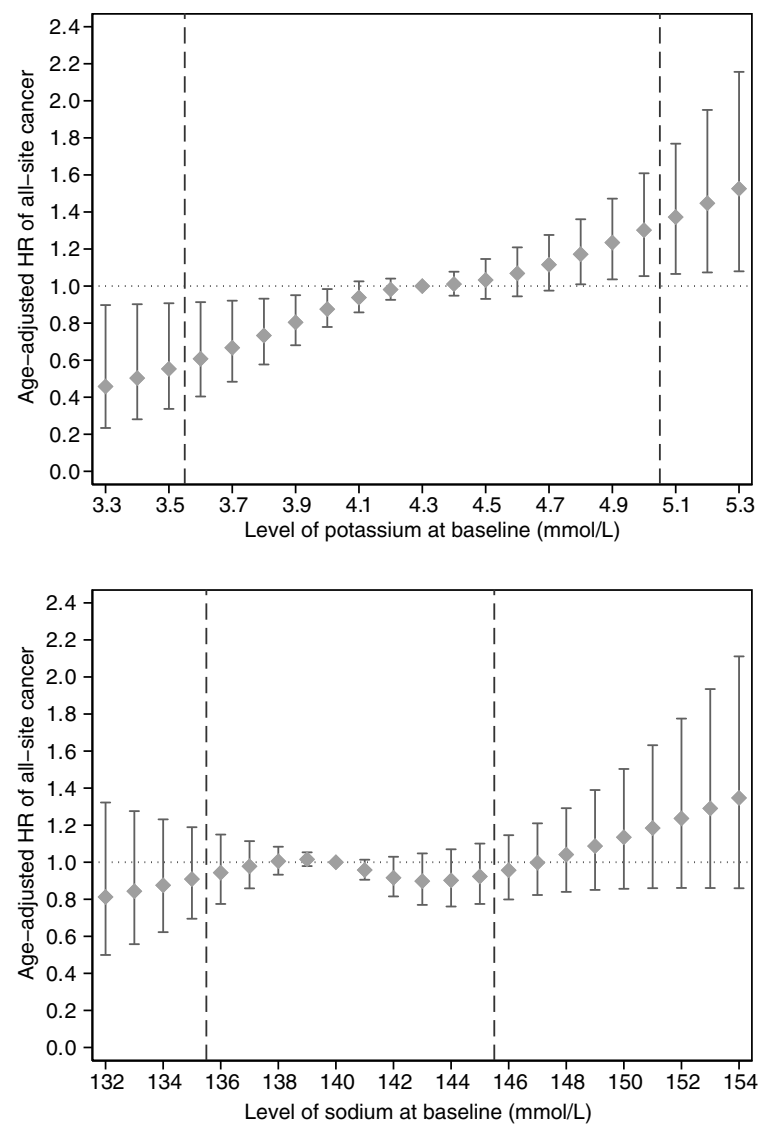

Figure 2 Hazard ratio for all-site cancer by levels of potassium and sodium. Bars indicate $95 \%$ confidence intervals. Restricted cubic spline function of potassium and sodium with four knots chosen according to Harrell's recommended percentiles. For potassium, the reference group was set to $\mathrm{K}=4.3 \mathrm{mmol} / \mathrm{L}$. Estimates for values $\leq 3.2$ and $\geq 5.4$ were not presented due to low numbers. Dashed lines indicate the cut-off values for hypokalemia $(\leq 3.5)$ and hyperkalemia $(>5.0)$. For sodium, reference group was set to $\mathrm{Na}=\mid 40 \mathrm{mmol} / \mathrm{L}$. Estimates for values $\leq|3|$ and $\geq \mid 55$ were not presented due to low numbers. Dashed lines indicate the cut-off values for hyponatremia $(<136)$ and hypernatremia $(>145)$.

are associated with subsequent cancer incidence. However, this study cannot reveal whether the relationship between individual serum level of potassium and cancer risk is causal, and several hypotheses can be suggested for future research. Firstly, higher level of serum potassium by itself may promote cancer development and growth through immune mechanisms. For example, it has been shown that potassium suppresses the activity of T cells, leading to a reduced ability to prevent cancer development. ${ }^{23}$

Secondly, individuals with elevated serum potassium may have an undiscovered cancer diagnosis at baseline resulting in potassium release from necrotic cancer cells (reverse causation). ${ }^{13}$ Our finding of a persistent increase in cancer risk after excluding the first 10-years of observation does not support this hypothesis. However, as it may
Table 4 Hazard Rate (HR) of All-Site Cancer Among Initially Healthy Men During 40 years of Follow-Up by Fasting Level of Potassium and Sodium at Baseline. The Standard Deviations (SD) for the Electrolytes Were $0.35 \mathrm{Mmol} / \mathrm{L}$ for Potassium and $3.5 \mathrm{mmol} / \mathrm{L}$ for Sodium

\begin{tabular}{|c|c|}
\hline & HR (95\% Cl) \\
\hline \multicolumn{2}{|l|}{ Potassium $(n=1989)$} \\
\hline Crude potassium (per SD) & $1.21(1.12-1.30)$ \\
\hline Age-adjusted ${ }^{\mathrm{a}}$ potassium (per SD) & $1.16(1.08-1.25)$ \\
\hline Adjusted ${ }^{\mathrm{b}}$ potassium (per SD) & $1.15(1.07-1.25)$ \\
\hline Adjusted $^{c}$ potassium (per SD) & $1.15(1.06-1.24)$ \\
\hline \multicolumn{2}{|l|}{$\begin{array}{l}\text { Potassium } \\
\text { Excluding first } 10 \text { years of follow-up }(n=1823)\end{array}$} \\
\hline Crude potassium (per SD) & $1.21(1.11-1.31)$ \\
\hline Age-adjusted ${ }^{\mathrm{a}}$ potassium (per SD) & $1.16(1.07-1.26)$ \\
\hline Adjusted $^{\mathrm{b}}$ potassium (per SD) & $1.16(1.07-1.26)$ \\
\hline Adjusted $^{c}$ potassium (per SD) & $1.16(1.07-1.26)$ \\
\hline \multicolumn{2}{|l|}{ Sodium $(n=1906)$} \\
\hline Crude sodium (per SD) & $1.00(0.93-1.08)$ \\
\hline Age-adjusted ${ }^{\mathrm{a}}$ sodium (per SD) & $1.02(0.95-1.10)$ \\
\hline Adjusted ${ }^{\mathrm{b}}$ sodium (per SD) & $1.03(0.95-1.11)$ \\
\hline Adjusted $^{\mathrm{d}}$ sodium (per SD) & $1.01(0.93-1.09)$ \\
\hline
\end{tabular}

Notes: adjusted for age at baseline. ${ }^{b}$ Additionally adjusted for body mass index, fitness, smoking, triglycerides, cholesterol, creatinine and sedimentation rate, all measured at baseline. 'Additionally adjusted for fasting sodium at baseline; ${ }^{\mathrm{d} A d d i t i o n a l l y ~ a d j u s t e d ~ f o r ~ f a s t i n g ~ p o t a s s i u m ~ a t ~ b a s e l i n e . ~}$

take several years to develop a cancer disease, ${ }^{24}$ we cannot rule out the possibility of reverse causation. ${ }^{25}$

Thirdly, there may be some inherent individual factors that contribute to the regulation of serum potassium that also facilitate cancer processes. For example, genetic variation in ion channels and pumps that are involved in potassium homeostasis may also be associated with genes that have a role in cell proliferations and differentiation. The SCNN1B gene is associated with serum potassium ${ }^{26}$ as well as gastric cancer ${ }^{9}$ and the KCNQ1 gene, which provides information for potassium channels, ${ }^{27}$ is also associated with the risk of colon, ${ }^{28}$ colorectal, ${ }^{29}$ and pancreatic cancer. ${ }^{30}$ Also, a polymorphism in the KCNJ4 gene, which encodes another potassium channel, is associated with prostate cancer. ${ }^{4}$ The research on membrane channels and transporters in cancer is still in the initial phase and can fill more gaps in the years to come.

The study has several strengths. First, the men were apparently healthy at inclusion that was confirmed by physical examination and review of medical records, and the men did not use any medication last 14 days. The examinations took place in the morning hours and the level of the 
Table 5 Hazard Rates (HR) for the Most Frequent Cancer Sites in the Cohort of Initially Healthy Men Followed for 40 Years. The Standard Deviation (SD) for Potassium Was $0.35 \mathrm{mmol} / \mathrm{L}$

\begin{tabular}{|l|l|l|l|}
\hline & ICD-7/ICD-I0 & Events & $\begin{array}{l}\text { Potassium } \\
\text { (Per SD) } \\
\text { Age-adjusted HR } \\
\text { (95\% Cl) }\end{array}$ \\
\hline Mouth, pharynx & $140-146 /$ C00-14 & 23 & $1.04(0.68-1.59)$ \\
Stomach & $151 / \mathrm{C} 16$ & 28 & $1.58(1.17-2.13)$ \\
Colon & $153 / \mathrm{C} 18-19$ & 81 & $0.94(0.75-1.18)$ \\
Rectum & $154 / \mathrm{C} 20-21$ & 40 & $1.08(0.79-1.49)$ \\
Pancreas & $157 / \mathrm{C} 25$ & 27 & $1.69(1.26-2.26)$ \\
Lung & $162 / \mathrm{C} 33-34$ & 104 & $1.32(1.09-1.59)$ \\
Prostate & $177 / \mathrm{C} 61$ & 204 & $1.16(1.01-1.34)$ \\
Kidney & $180 / \mathrm{C} 64$ & 32 & $0.94(0.66-1.34)$ \\
Bladder & $181 / \mathrm{C} 67-68$ & 73 & $1.12(0.88-1.42)$ \\
Melanoma & $190-191 / C 43-44$ & 87 & $1.06(0.85-1.32)$ \\
Lymphoma, & $206-207 / \mathrm{C} 8 \mathrm{I}-95$ & 61 & $1.14(0.88-1.48)$ \\
leukemia & & & \\
\hline
\end{tabular}

Notes: ICD-7/ICD-10= the 7 th and the 10 th edition of the World Health Organization's International Classification of Diseases codes for cancer; Events=number of cancer cases.

electrolytes was measured fasting. Several potential confounding factors were adjusted for in the analysis (eg, physical fitness, smoking, and diet (approximated by triglycerides, cholesterol, and body mass index)), and the individuals were followed for cancer for until 40 years. The cohort was representative of the age-group of men within the given time-period, with regard to cancer incidence in their counties of residence. ${ }^{31}$ Thus, the results are considered to be generalizable to healthy men in northern Europe.

Some limitations should be noted. The study protocol included men only and was originally not designed for investigating the aim of the present study. The study sample was relatively small and no information on social status, alcohol intake, diet and genetic variations was available. Lack of repeated measures may cause bias due to change in potentially confounding exposures (e.g. physical fitness and use of medication) during follow-up. Due to the small number of events of site-specific cancers, these results should be interpreted with caution. Moreover, due to the long follow-up time, the risk of competing death could potentially preclude the interpretation of the results from Cox-regression analysis for all-site cancer. However, since the risk of competing death also increases by the level of potassium this bias is expected to be minor.

\section{Conclusion}

The finding that fasting serum potassium was strongly associated with long-term cancer risk in healthy individuals points to further research in several directions, eg, the influence of potassium in cancer-fighting immune mechanisms or the role of potassium or potassium ion channels in cell proliferation and differentiation. The strength of the association suggests possible clinical implications, eg, medical surveillance strategies of individuals with high levels of potassium.

\section{Availability of Data and Material}

Data are from the Oslo Ischemia Study. Public availability would compromise the privacy of the respondents. According to the approval from the Norwegian Regional committees for medical and health research ethics, the data is to be stored properly and in line with the Norwegian Law of privacy protection. Aggregated data are available on request.

\section{Author Contributions}

All authors contributed toward data analysis, drafting and critically revising the paper, gave final approval of the version to be published, and agree to be accountable for all aspects of the work.

\section{Disclosure}

The authors report no conflicts of interest in this work.

\section{References}

1. Jansson B. Dietary, total body, and intracellular potassium-to-sodium ratios and their influence on cancer. Cancer Detect Prev. 1990;14:563-565.

2. Jansson B. Potassium, sodium, and cancer: a review. J Environ Pathol Toxicol Oncol. 1996;15:65-73.

3. Jiang S, Zhu L, Yang J, et al. Integrated expression profiling of potassium channels identifys KCNN4 as a prognostic biomarker of pancreatic cancer. Biochem Biophys Res Commun. 2017;494:113-119. doi:10.1016/j.bbrc.2017.10.072

4. Kim YS, Kim Y, Choi JW, Oh HE, Lee JH. Genetic variants and risk of prostate cancer using pathway analysis of a genome-wide association study. Neoplasma. 2016;63:629-634. doi:10.4149/neo_2016_418

5. Huang X, Jan LY. Targeting potassium channels in cancer. J Cell Biol. 2014;206:151-162. doi:10.1083/jcb.201404136

6. Litan A, Langhans SA. Cancer as a channelopathy: ion channels and pumps in tumor development and progression. Front Cell Neurosci. 2015;9:86. doi:10.3389/fncel.2015.00086

7. Peruzzo R, Biasutto L, Szabò I, Leanza L. Impact of intracellular ion channels on cancer development and progression. Eur Biophys J. 2016;45:685-707.

8. Cázares-Ordoñez V, Pardo LA. Kv10.1 potassium channel: from the brain to the tumors. Biochem Cell Biol. 2017;95:531-536. doi:10.1139/bcb-2017-0062

9. Qian Y, Wong CC, Xu J, et al. Sodium channel subunit SCNN1B suppresses gastric cancer growth and metastasis via GRP78 degradation. Cancer Res. 2017;77:1968-1982. doi:10.1158/00085472.CAN-16-1595

10. Wang SH, Wang KL, Yang WK, Lee TH, Lo WY, Lee JD. Expression and potential roles of sodium-potassium ATPase and E-cadherin in human gastric adenocarcinoma. PLoS One. 2017;12: e0183692. doi:10.1371/journal.pone.0183692 
11. Ramírez A, Vera E, Gamboa-Domínguez A, Lambert P, Gariglio P, Camacho J. Calcium-activated potassium channels as potential early markers of human cervical cancer. Oncol Lett. 2018;15:7249-7254. doi:10.3892/ol.2018.8187

12. Kolanjiappan K, Manoharan S, Kayalvizhi M. Measurement of erythrocyte lipids, lipid peroxidation, antioxidants and osmotic fragility in cervical cancer patients. Clin Chim Acta. 2002;326:143-149. doi:10.1016/S0009-8981(02)00300-5

13. Wilson FP, Berns JS. Tumor lysis syndrome: new challenges and recent advances. Adv Chronic Kidney Dis. 2014;21:18-26. doi:10.1053/j.ackd.2013.07.001

14. Mirrakhimov AE, Ali AM, Khan M, Barbaryan A. Tumor lysis syndrome in solid tumors: an up to date review of the literature. Rare Tumors. 2014;6:5389. doi:10.4081/rt.2014.5389

15. Erikssen J, Skrede S. Serum lipids and latent coronary insufficiency. Scand J Clin Lab Invest. 1977;37:243-250. doi:10.1080/ 00365517709091489

16. Erikssen G, Liestøl K, Bjørnholt J, Thaulow E, Sandvik L, Erikssen J. Changes in physical fitness and changes in mortality. Lancet. 1998;352:759-762. doi:10.1016/S0140-6736(98)02268-5

17. Falk RS, Tretli S, Paulsen JE, Sandvik L, Erikssen J, Heir T. Response to intravenous glucose-tolerance test and risk of cancer: a long-term prospective cohort study. EBio Med. 2017;21: 117-122.

18. Larsen IK, Småstuen M, Johannesen TB, et al. Data quality at the cancer registry of Norway: an overview of comparability, completeness, validity and timeliness. Eur J Cancer. 2009;45:1218-1231. doi:10.1016/j.ejca.2008.10.037

19. Gumz ML, Rabinowitz L, Wingo CS. An integrated view of potassium homeostasis. $N$ Engl J Med. 2015;373:60-72. doi:10.1056/ NEJMra1313341

20. Adrogué HJ, Madias NE. Hyopnatremia. $N$ Engl J Med. 2000;342:1581-1589. doi:10.1056/NEJM200005253422107
21. Adrogué HJ, Madias NE. Hypernatremia. $N$ Engl J Med. 2000;342:1493-1499. doi:10.1056/NEJM200005183422006

22. StataCorp. Stata Statistical Software: Release 15. College Station, TX: StataCorp LCC; 2017.

23. Eil R, Vodnala SK, Clever D, et al. Ionic immune suppression within the tumour microenvironment limits T cell effector function. Nature. 2016;537:539-543. doi:10.1038/nature19364

24. Mooi WJ, Peeper DS. Oncogene-induced cell senescence-halting on the road to cancer. $N$ Engl J Med. 2006;355:1037-1046. doi:10.1056/ NEJMra062285

25. Friberg S, Mattson S. On the growth rates of human malignant tumors: implications for medical decision making. J Surg Oncol. 1997;65:284-297. doi:10.1002/(ISSN)1096-9098

26. Gaukrodger N, Avery PJ, Keavney B. Plasma potassium level is associated with common genetic variation in the beta-subunit of the epithelial sodium channel. Am J Physiol Regul Integr Comp Physiol. 2008;294:R1068-72. doi:10.1152/ajpregu.00732.2007

27. Abbott GW. Biology of the KCNQ1 potassium channel. New J Sci. 2014;2014:1-26. doi:10.1155/2014/237431

28. den Uil SH, Coupé VM, Linnekamp JF, et al. Loss of KCNQ1 expression in stage II and stage III colon cancer is a strong prognostic factor for disease recurrence. $\mathrm{Br} J$ Cancer. 2016;115:1565-1574. doi:10.1038/bjc.2016.376

29. Than BL, Goos JA, Sarver AL, et al. The role of KCNQ1 in mouse and human gastrointestinal cancers. Oncogene. 2014;33:3861-3868. doi:10.1038/onc.2013.350

30. Kuruma S, Egawa N, Kurata M, et al. Case-control study of diabetes-related genetic variants and pancreatic cancer risk in Japan. World J Gastroenterol. 2014;20:17456-17462. doi:10.3748/wjg.v20. i46. 17456

31. Heir T, Falk RS, Robsahm TE, Sandvik L, Erikssen J, Tretli S. Cholesterol and prostate cancer risk: a long-term prospective cohort study. BMC Cancer. 2016;16:643. doi:10.1186/s12885-016-2691-5
Clinical Epidemiology

\section{Publish your work in this journal}

Clinical Epidemiology is an international, peer-reviewed, open access, online journal focusing on disease and drug epidemiology, identification of risk factors and screening procedures to develop optimal preventative initiatives and programs. Specific topics include: diagnosis, prognosis, treatment, screening, prevention, risk factor modification, systematic reviews, risk \& safety of medical interventions, epidemiology \& biostatistical methods, and evaluation of guidelines, translational medicine, health policies \& economic evaluations. The manuscript management system is completely online and includes a very quick and fair peer-review system, which is all easy to use.

\section{Dovepress}

